\title{
Heritage Tourism and Vibrant Life of the Baan Lao Community, Chao Phraya River, Bangkok, Thailand
}

\author{
Korakit Choomgrant ${ }^{1}$ and Renu Sukharomana ${ }^{2, *}$
}

${ }^{1}$ Faculty of Social Sciences, Kasetsart University, Bangkok, Thailand

${ }^{2}$ Institute for Social and Economic Sciences, Dhurakij Pundit University, Bangkok, Thailand

\begin{abstract}
The reputations of primary and secondary tourist destinations are hierarchically created through its value to the nation. Prioritizing a conservation project and tourism development can have major differences. Values attached to a destination by inhabitants are different from those of tourists, and are often influenced by the promotional campaigns designed by authorized agencies. A primary destination is then worthy of promotion and conservation as it serves a nation's purposes economically, socially and politically, while a destination that is not corresponding in such ways is usually disregarded. Koh Kret is an established primary tourism destination for domestic visitors, though not for international visitors. However, the Baan Lao Community can be developed as a secondary tourism destination for visitors to Koh Kret. Koh Kret and Baan Lao Community in Thailand are illustrations of significance and value. By understanding the Baan Lao community's significance, value and values, it is an opportunity to develop the area as a secondary tourist destination, and help preserve the way of life of local inhabitants along the Chao Phraya River in Bangkok, Thailand.
\end{abstract}

Keywords: Primary tourism destination, Secondary tourism destination, Koh Kret, Associated heritage value, Way of life, Chao Phraya River.

\section{INTRODUCTION}

This paper establishes and provides a deeper understanding regarding the differences between primary and secondary tourism destinations. An alternative tourist destination is presented in the Pakkret precinct, apart from the famous iconic islandKoh Kret or Kret Island. Baan Lao ${ }^{1}$ is located within an approachable distance from the Northern outskirts of Bangkok, and has unspoilt nature and culture along the Chao Phraya River from the Ku temple (Wat Ku) to Poe Baan Aoy temple (Wat Poe Baan Aoy).

This area includes the local people's unique way of life, with its distinctive characteristics, that has been passed on from generation to generation. Moreover, this area can also be a piece of the jigsaw for those who would like to understand the lost story of the Pakkret community, near the Chao Phraya River. Therefore, this paper explains the important terms, including primary destination, secondary destination, and associated heritage value.

*Address of correspondence to this author at the Institute for Social and Economic Sciences, Dhurakij Pundit University, Bangkok, Thailand;

Tel: (66)29547300 Ext. 361-2; Fax: (66)25800064;

E-mail: sukharenu@gmail.com

JEL: L83, Q57, Z32.

${ }^{1}$ Baan Lao was named more than a century ago by the local people within the Pakkret precinct. This area was once a large area of sugarcane plantations, with people from Laos working in this area, as well as the "Rong Heep" community (literally translated as sugarcane mill) located next to the Baan Lao community. This indicates the close relationships between the communities.
The second part will present the benefits derived from developing a secondary tourism destination for companies, tourists and people associated with the site. The last part will take a Baan Lao community by the Chao Phraya River as a case study of a secondary tourism destination, and propose a management plan for the area.

\section{PRIMARY AND SECONDARY DESTINATIONS, AND ASSOCIATED HERITAGE VALUE}

The landmarks of each country are often heavily promoted as icons, or as main destinations for the tourism industry to attract domestic and international tourists and generate revenue for the destination. Employing such promotional campaigns leads to many problems, such as the situation of gentrification in the case of Venice, Italy. The large concentration of tourists in some places, with fewer tourists in others, can be seen clearly in the case of Hong Kong (Du Cros, 2002). The aforementioned predicaments lead to various problems including, for instance, the unequal distribution of income, the loss of local cultural identity due to the commodification of intangible heritage, and the destruction of tangible heritage caused by large numbers of tourists.

Such problems will continually arise as long as the main attractions are repeatedly promoted while other potential destinations are ignored. This might result from several reasons. There is an interesting analysis as to why other destinations have not gained much attention from tourists. This implies that, in addition to 
the knowledge gained while touring, entertainment and enjoyment are valued tourist experiences, and that tourists may perceive that other destinations do not provide similar experiences as those of the major destinations (Du Cros, 2002).

According to this analysis, it is possible to infer that whatever provides tourist experiences could be stated as attractions. In other words, whenever tourists consider gaining greater experience at a specific destination, it would then be regarded as a primary destination.

It is necessary to establish an understanding regarding the terms 'primary' and 'secondary' tourism destinations for tour operators, and provide the knowledge of associated heritage values. This will enable tour operators to develop itineraries that provide benefits not only for the company, but also for tourists, who can enjoy new experiences, and for people in the community, who will receive greater benefits. The Baan Lao community is considered and illustrated as a case study.

In a sense, a secondary tourist destination might be interpreted as being consistent with the late and beloved King Bhumibol Adulyadej (Rama IX) emphasis on the "sufficiency economy". This can also be interpreted as "Heritage and Cultural" economy.

\section{Primary and Secondary Destinations}

It is recommended that tourist destinations are hierarchically different and can be divided into three categories: primary, secondary and tertiary destinations $^{2}$. At this stage, only the definitions of primary and secondary destinations will be introduced. Primary destination refers to heritage assets that will draw tourists to a destination in their own right, and the attractions are usually spectacular (Du Cros, 2002, p. 319). A secondary destination will only appeal to tourists once they are already at a destination and are examining the options for the best use of their time. Therefore, secondary refers to a more discretionary choice for tourists (Du Cros, 2002, p. 319).

Following this illustration, excellent examples of primary tourism destinations are Bangkok and Central Java because these two destinations contain heritage-

\footnotetext{
${ }^{2}$ Tertiary destination is the most discretionary choice, which is usually a common site type or occurs in more remote places that are not well known. For further details, see Du Cros, 2002, pp. 319-321.
}

based attractions, including the Emerald Buddha temple and Borobudur, respectively. Notably, these two destinations are very well known internationally, and are crowded. Samut Sakorn and East Java are less popular because there have no spectacular attractions, where experiences could be obtained as equivalent as the Emerald Buddha Temple of Bangkok and Borobudur of East Java.

In addition, when assigning the "primary" or "secondary" status to a destination, it is also important to take the value into consideration. Generally, it seems that a place/site with high value will be regarded as an icon or a main destination because it represents a nation's identity, or is a symbol of the country (see Choomgrant, 2015b). A place/site with lower value is usually disregarded. There are four main types of value which underpin the decision as to whether a heritage site is worthy of conservation, namely aesthetic value, historic value, scientific value, and social value (Australian ICOMOS 1999, p. 12-13, also known as The Burra Charter).

Although the place/site may possess lower value than those of national representations, it might have high values for local inhabitants as it can significantly represent the collective local identity, or what current scholars proposed as a "heritage making process" (see Smith 2006, Harrison 2013, and Choomgrant 2014).

Taylor (2004, p. 419) posted a very provocative question in relation to values: "Whose values are we addressing and whose heritage is it?", and also gave a very meaningful statement which emphasizes the importance of subjectivity in regard to value: "The tangible fabric of heritage places and objects is capable of objective quantification, but it is the values we attach to places and objects that are the fuel of the fire of heritage".

The two aforementioned questions are worth considering as assigning a value to a place is very subjective, and involves hierarchical power. Values assigned by central government are, of course, greater than values assigned by local people because it reflects a different scale of significance. As mentioned above, a destination where the country's identity is presented has high value nationally and internationally, such as the World Heritage Sites of Ayutthaya and Sukhothai in Thailand.

Most primary destinations are regarded as very important. A secondary destination may not have as 
high a value as a primary one, but may have very high value for a local community or for a specific group of people, such as the historical parks in Thailand, including the Panom Rung Stone Sanctuary in Burirum province (see Denes 2012a, 2012b; Choomgrant 2015a)

A primary destination does not refer only to tangible and intangible heritage on a national scale, but also on a smaller scale, including a region, a province, and a city or within a community. For example, Panom Rung Stone Sanctuary is a primary destination in Burirum province, while Muang Tam Stone Sanctuary is regarded as a secondary destination. Both are located in the same province, but the two historic sites are given different levels of significance (for further details, see Choomgrant 2014, Chapter 3 ).

However, in relation to assessing the significance of heritage places, Taylor (2004, p. 427) reminds us that "significance is itself a human judgmental value, difficult to quantify, particularly by ranking it...but non-material culture, the traditions and practices that have created the places we value and give them meaning, and the memories they entail, are more difficult to rationalize and protect".

In a nutshell, primary and secondary tourism destinations can be differentiated by two methods; first, by the number of tourists that visit the places at different levels, the budget provided to develop the places, and the attention people pay to the places; second, by assessing the value people put on the place. All in all, the status of primary and secondary tourism destinations is not created naturally as it can be an arbitrary human creation.

\section{Associated Heritage Value and Attractions of the Secondary Destination}

As stated above, emphasis will be given to a secondary destination. The associated heritage value and attractions of the secondary destination will also be analyzed in this part.

Taylor (2004) suggested that people normally place value on knowing about the history of events, places and people through time, and not just distant history, but also the present (Taylor 2004, p. 420). Although it applies to popular heritage, it is useful to consider these facts in order to develop a secondary site to be a tourist destination. Apart from the mentioned value, cultural significance is also necessary to understand because it is a "concept which helps in estimating the value of places. The places that are likely to be of significance are those which help an understanding of the past or enrich the present, and which will be of value to future generations" (Australian ICOMOS 1999, p. 12).

The Burra Charter also identified four main values: aesthetic value, historic value, scientific value and social value (Australian ICOMOS 1999, pp. 12-13). These four main values are used to assess the significance of tangible and intangible heritage. Taylor (2004, p. 426) introduced additional types of value that may be useful in conservation studies, including interpretative value, associative value and integrity. The following is an explanation of associative value which is useful to understand the notion of a secondary destination:

"The ability to put into context what has occurred and who promoted the actions; this value hinges on a knowledge and understanding of the way our predecessors have been involved in place making. It is a powerful value related to our need to understand past human actions and the people who participated. It is very much a sense of a link with the past and the resultant values and meanings people attach to places. This value meshes with social value. Both underpin and emphasize the focal position of meaning and symbolism of places in cultural heritage management practice"

As an illustration, the pivotal point of associative value is relevant to the ability to connect the past and the present through human actions and the people attached to the destination. This value focuses on people's everyday life, apart from the 3Ps of Prince, Priests and Politicians (Taylor, 2010, p. 2). It is a value that allows people to be part of the place and builds up a sense of place where the tangible and intangible coalesce (Taylor, 2010, p.2). Metaphorically, the associated heritage value resembles a piece of a jigsaw. When placing it on the board, the whole story or picture becomes clearer and more understandable. Hence, associated heritage value is an important factor that helps create the identity of a destination.

Associated heritage value could be used in two ways in the case of a secondary destination. First, a secondary destination is where significant cultural value is evident but is lower than that of a primary 
destination. In order to clarify the notion of a secondary place, associated heritage value should be present in a way that makes the destination distinctive with an authentic identity. Second, the associated heritage value of a secondary destination, apart from making the destination distinctive, could possibly link it with the primary destination.

The attractiveness of the secondary destination is associated with the primary attraction. From the two suggestions, it can be said that the beauty, serenity or charm of the secondary destination are not major attractions. The ability of associated heritage value to represent the involvement between people, historic events, and places through time should be prioritized.

In summary, associated heritage value is a potential additional value and is appropriate to apply in case of a secondary destination, which is perceived to have lower aesthetic, historic, scientific or social value than a primary destination. It is useful for tour operators or tourism management companies to promote this value to tourists, and to develop itineraries to match the needs of tourists, who wish to acquire knowledge and enjoyment. It is also beneficial to the associated people and community in various ways.

\section{POTENTIAL BENEFITS TO THE COMPANY, TOURISTS AND OTHERS}

The plan to develop a secondary destination will not succeed if there is no co-operation among stakeholders. Moreover, if there is no sign of potential benefits, the tourism management company, tourists and people associated with the area might not be interested in and might ignore the plan. Hence, it is important to clarify the potential benefits in order to convince all stakeholders to accept and develop the appropriate tourism plans.

\section{Benefits to the Company}

As the company's plan is to search for any possibility to expand the secondary cultural tourism destinations in Thailand, it is crucial for the company to understand the definition of culture and cultural heritage agreed upon by the ASEAN member countries, as follows:

"Culture means the whole complex of distinctive spiritual, intellectual, emotional and material features that characterize a society or social group. It includes arts and letters as well as human modes of life, value system, creativity, knowledge systems, traditions and beliefs"(ASEAN Declaration on Cultural Heritage, 2000, $p$. 3).

Cultural heritage, as defined by the ASEAN clarification on Cultural Heritage, includes both tangible and intangible heritage. The definitions are relevant to the values derived from different types of heritage. Considering the associate heritage value discussed above, there is an interesting definition, as follows:

"Site and human habitats: human creations or combined human creations and nature, archaeological sites and sites of living human communities that are of outstanding value from a historical, aesthetic, anthropological or ecological viewpoint, or, because of its natural features, of considerable importance as habitat for cultural survival and identity of particular living traditions" (ASEAN Declaration on Cultural Heritage, 2000, p. 3).

Once the company successfully explores an opportunity to expand its tourism destination as a secondary attraction, and decides to develop a secondary destination, it will help increase the reputation of the company (adapted and summarized from Yunis, 2004, Du Cros, 2002, Logan, 2001, and Sullivan, 1993) as follows:

1. A poverty alleviator and job creator. As stated earlier, a secondary destination is normally located in a remote area and people in the community may not have an equal chance to obtain benefits in contrast with people who live in primary destination areas.

2. Poverty is the main problem which could be alleviated by this plan, as it would help to alleviate poverty by providing jobs related to tourism activities, such as local tour guides, food sellers and staff at hotels and restaurants.

3. A supporter of traditional activities and a builder in the community. This point is relevant because many people leave the communities and traditional occupations to have a better career and life elsewhere, usually in larger cities. Once there are tourists visiting the secondary destination, there is a greater likelihood that people will stay in their own residential area. 
Moreover, people are proud of their traditions and way of life as greater attention is paid to their community, and they will have a greater sense of place and feeling that they are part of the community.

On the one hand, a tourism management company can provide more options for tourists who may have different desires and needs, and wish to be away from densely populated destinations. It will also help to reduce the destruction of the primary destination arising from excessive tourism numbers. Moreover, it helps promote the practice of developing a secondary destination for other agencies, and can be a model of tourism planning for other organizations.

\section{Benefits to Tourists and People Associated with the Secondary Destination}

Experience is the key word for what tourists seek while travelling, and not only knowledge, but also entertainment should be provided (Du Cros, 2002, p. $319)$. Hence the obvious benefit which tourists receive is knowledge about the destination from a different perspective and with a less commercialized purpose.

1. As an illustration, tourists will learn about the significance of the destination in terms of associated heritage value, which will highlight the identity of the destination, the distinctive characteristics and the relationship between people, places and events, in addition to the national view of the primary destination.

2. Since most of the secondary destinations are located in remote areas, tourists can expect to witness different picturesque landscapes in the area, including emotion-related scenery and eyefood. Happiness might not be derived from comfort or performance, but from the feeling that they are helping the community fight against the poverty while preserving the local identity.

People associated with the secondary destination will gain various benefits:

1. A decrease in poverty. This is because people will receive income and revenue flows from tourism activities undertaken in the community. This money will be spent enhancing their quality of life, for instance, spending on their children's education and modern medical treatments.

2. Referring to the Hoi An protocols, the preservation practice is followed to protect "diverse and enduring cultural identities" (UNESCO Bangkok, 2009, p. 2 and also known as the Hoi An Protocol). In addition, it will encourage public understanding of the need to conserve heritage and the localization of stewardship responsibility over heritage resources (UNESCO Bangkok, 2009, p. 3). In other words, if people in the community begin to preserve and protect their cultural heritage, this will enhance the awareness of the public to understand and support the local people.

3. The sense of place is strengthened through the awareness and importance of their cultural heritage, which gains attention from not only the local level, but also the regional or national level. People would be proud of their heritage and identity.

The relevant stakeholders may share the benefits more equally. Although the benefits listed above might be both measurable and immeasurable, it is better than leaving a secondary destination unattended and unprotected. Finally, it will lead to many problems ${ }^{3}$ listed in the Hoi An Protocols (UNESCO Bangkok, 2009, p. 3).

In short, the aforementioned benefits are evaluated and analyzed empirically based on past experiences from many sites around the world. Thus, it is more useful to provide "A Vibrant Way of Life by the Chao Phraya River in the Baan Lao Community" as a case study of secondary tourism destination development to identify the cultural value as well as to present and interpret it for visitors. This is described in detail in the following section.

\section{A VIBRANT LIFE BY THE CHAO PHRAYA RIVER OF BAAN LAO COMMUNITY}

The only reputable, and domestically and internationally famous destination in Pakkret, Nonthaburi province, is "Koh Kret" ${ }^{4}$ (Kret Island), located opposite the Pakkret pier on the left bank of the river. Koh Kret has been continuously and generally

\footnotetext{
${ }^{3}$ There are five negative consequences, including: 1) Dismemberment of a heritage site, with the loss of integrity; 2) Dilapidation and structural deterioration; 3) Replacement of original components with counterfeit and nonindigenous technologies and materials; 4) Loss of sense of place; and 5) Disenfranchisement of heritage from the tradition of community use.

${ }^{4}$ There is a large number of research papers, theses, books and articles about Koh Kret. This shows that much scholarly attention is paid to this small artificial island. Koh Kret is also highlighted as a main destination for those who wish to travel to Pakkret in many tour itineraries or guidebooks.
} 
promoted as a place which represents the harmony of the ethnic minority Mon and Thai groups living and sharing culture and traditions in the same district. Therefore, it creates the notion of Koh Kret as an icon of Pakkret as a tourist destination.

On weekends, the artificial island is very popular among tourists. Koh Kret is significant for both the local and provincial governments as it brings tourists and revenue to the areas as well as many job opportunities and interactions between locals and tourists. These characteristics make Koh Kret a primary destination in Pakkret.

Historically, since the Ayutthaya period, Pakkret was known as a part of Baan Talad Kwan (Kwan market village) in many western documents. It was known as an area where people carried out rice and fruit cultivation, and as a port for international merchants who stopped before reaching the capital city of Ayutthaya (for further details, see Fine Arts Department, 1999, and Boonpuk, 2007).

In addition, the Chao Phraya River flows through the area of Pakkre, which made the lives of people closely connected with the river, and can still be seen in other parts of Pakkret. Thus, the area from the $\mathrm{Ku}$ temple to the Poe Baan Aoy temple is called the Baan Lao community, and reflects the way of life of people both in the past and present.

Considering the geographical features of the area of study, this area is on the east bank of the Chao Phraya River, where the land is fertile and abundant, while the opposite side has been eroded by river flows. Therefore, the settlements and way of life of the people on the two sides of the Chao Phraya River are quite different.

People on the west bank of the river have to be aware of the erosion of their land, and water plant cultivation is not possible, while the people on the other side do not have woes about building their houses on the river and are able to continue their traditional water plant cultivation and fishing traditions. Moreover, there is a large green hinterland, where people carry out fruit and rice cultivation. The following part will focus on the significance and value of the area of the case study (see Photos 1-3).

\section{Significant Cultural Value: A Vibrant Way of Life by the River}

This area, which is defined as a secondary destination, may not have as much cultural value as Koh Kret. It reflects the way of life by the river, and the traditions and activities in relation to the geographical characteristics, which build up the identity of the community as part of Pakkret. In other words, it has potential associated heritage value.

There are three main reasons to support the associated heritage value of this area, as follows:

1. People who live in this area have inherited the traditions, cultures and activities from previous generations. Those have been sustained and blended with modern technologies and living.

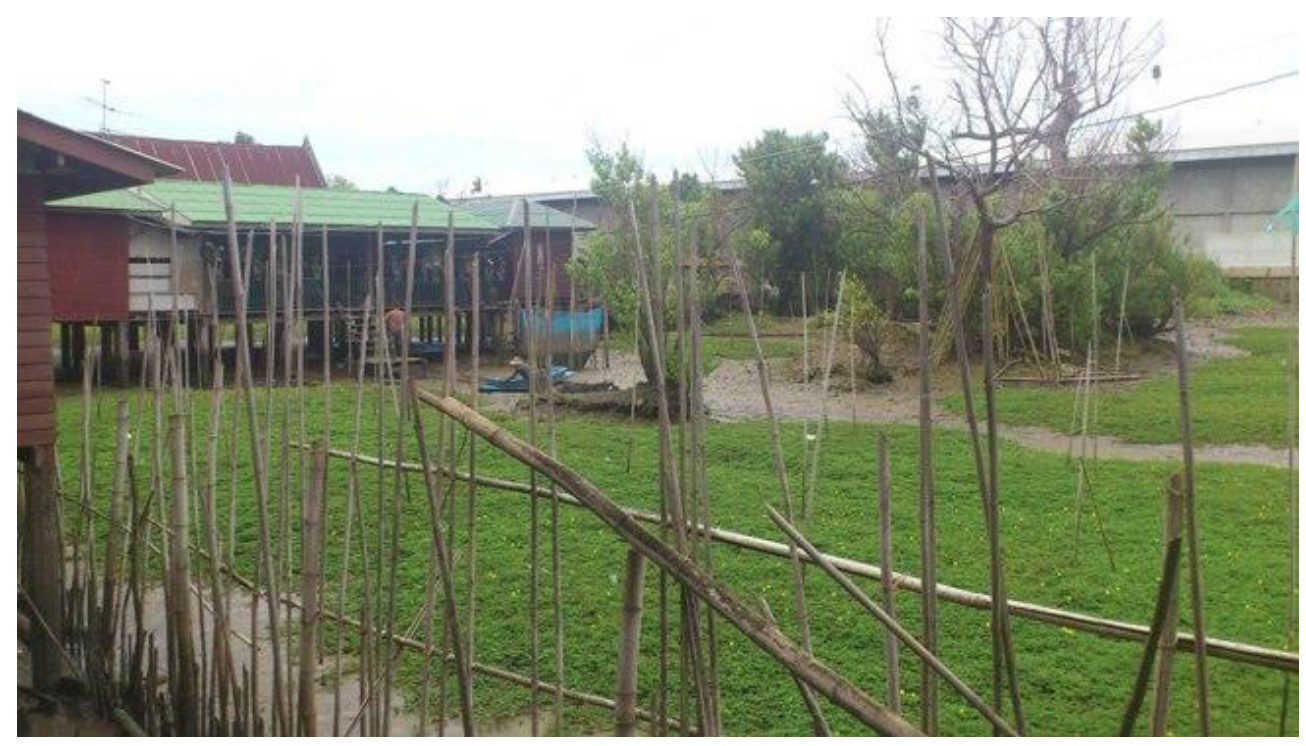

Photo 1: Water plant cultivation and fishing activities.

Source: Korakit Choomgrnt, 3 January 2016. 


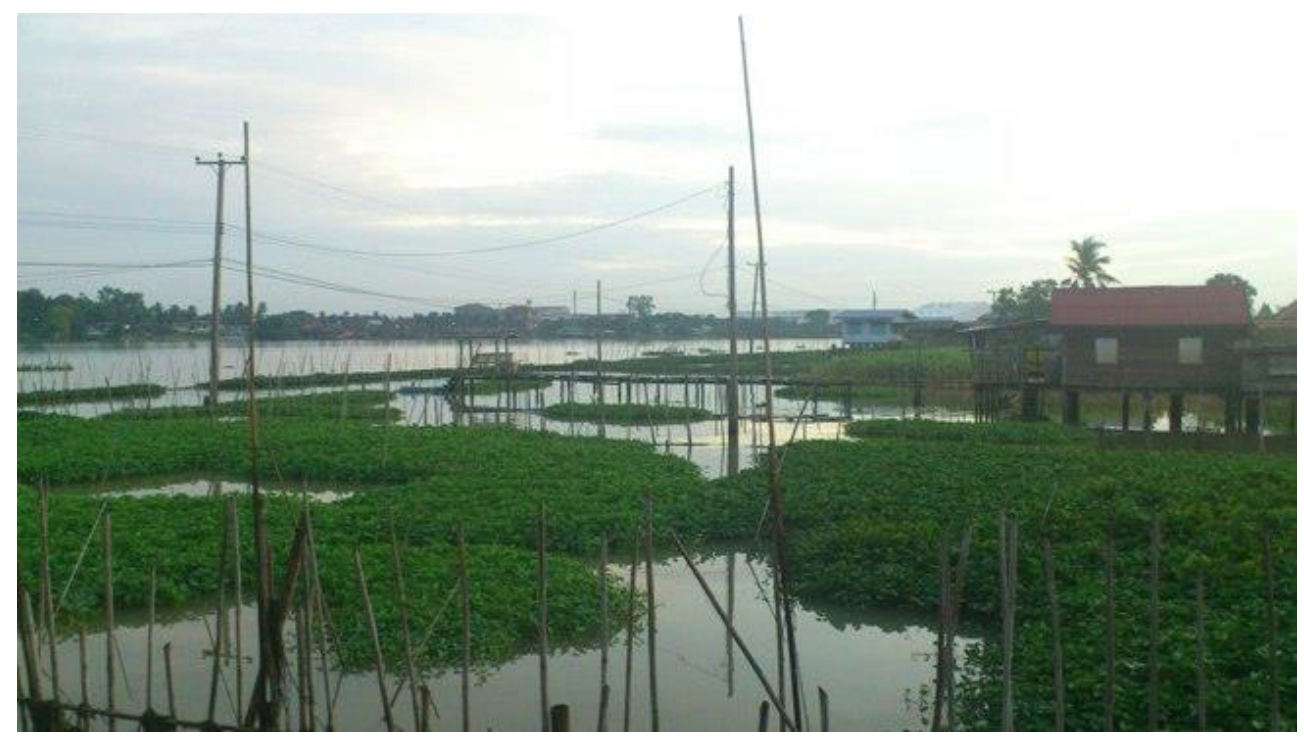

Photo 2: Water plant cultivation and houses along the river.

Source: Korakit Choomgrant, 3 January 2016.

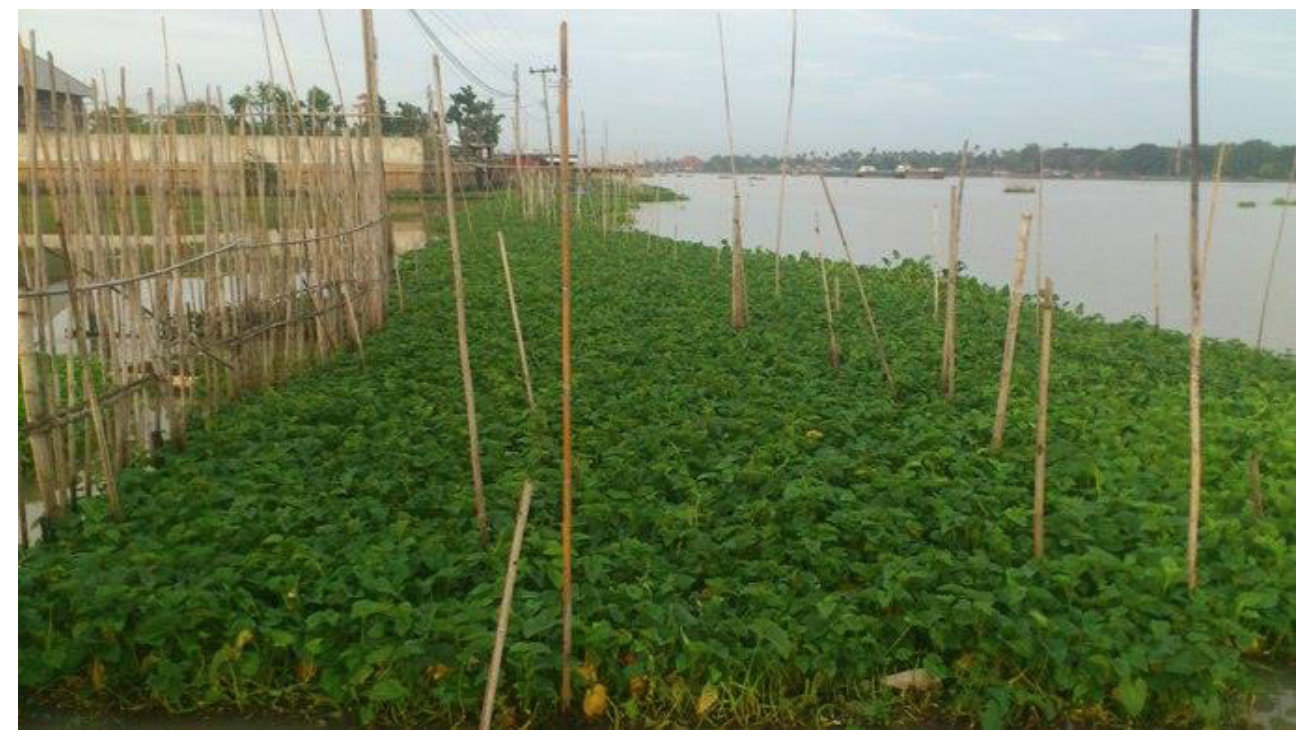

Photo 3: A stunning scene of water plant cultivation along the riverside.

Source: Korakit Choomgrant, 3 January 2016.

Although some of the people in the area are not dependent on water plant cultivation and fishing, they still do it as part of everyday family activities. They sometimes bring the product to sell at the market at Ku temple every Tuesday and Thursday (from a discussion with 3 locals on 3 January 2016).

2. The kinship relationship of people in this area is strong and tight. On the day of observation, one householder (see Photo 1) was fishing by using a fish net and stretched the net to the houses nearby. It reflects the good relationship between people, otherwise they would have to restrict using the net within their own area. In addition, it seems that they know each other quite well through other activities, such as wedding ceremonies, religious ceremonies and agricultural activities.

3. Though there is a new generation who might receive influences from outside and decide to move to another area, such as a large city, these people still continue with their family's way of life, while they wisely combine modern technologies and traditional ways of life. For instance, they 
use air-conditioning, washing machines, automobiles and the internet. It might be assumed that the new generation is as proud of their way of life, as much as it is appreciated by outsiders.

From the reasons above, this area is worth developing by focusing on the associated heritage value and adding some entertaining activities for tourists. It will enhance the significance of the area, where the intactness of culture and nature are evident, tourists can experience authentic ways of life, and the missing stories of another community are disseminated as part of Pakkret.

\section{Presentation and Interpretation and the Involvement of the Local Community}

Associated heritage value assessed in the former part is a central point of the area: presentation and interpretation have to be done carefully because it deals with the sensitive and intangible values of the community. It is essential to invite the relevant stakeholders to discuss and plan. Nonetheless, presentation and interpretation should not be overstated, as it should be truthful and sustainable.

Comments on how associated heritage value might be interpreted and presented are as follows:

1. The water level is crucial for presentation, and it might be sensible to bring this issue into consideration before arranging any activities. As people live by the river and conduct water plant cultivation, tourists should be allowed to witness and participate in these activities when the water level is adequate for such activities so as to increase greater interactive experiences for tourists.

2. The story and history of this area should be told in order to identify the connection and intactness of the entire area of Pakkret by highlighting the settlement patterns of people in this area, how their traditions and cultures are related to nature, and the adaptation of people from generation to generation by giving some examples of new technologies and modern equipment used in the area. This requires well-trained tour guides or knowledgeable local people who could convey the correct information to visitors. Well-designed tourism brochures should also be provided.
3. Fishing and trapping water animals can be seasonal, so the activities should not accommodate tourist visits. Tourists should follow seasonal activities; otherwise, cultures and traditions will be commodified, which can lead to the loss of authenticity and integrity.

4. In order to retain tourist visitor interest and enhance their experience, participation in some authentic activities should be allowed, such as cultivating water plants.

5. Limit the number of visitors safeguards against the possible destruction of nature and the culture of people in the community. Moreover, it stops the community becoming commercialized and makes the area more appealing and attractive. In short, attention should be paid to the local people's way of life.

The last section will present suggestions regarding the involvement of the local people. As discussed, people are at the center of cultural heritage management and are equal in importance to the associated heritage value. The first priority should be given to the local people in terms of their needs, their opinions and suggestions as they live in the community, and all tourism visitors impact directly influence their lives.

"Recognizing that communities, in
particular indigenous communities, groups
and, in some cases, individuals, play an
important role in the production, safeguar-
ding, maintenance and re-creation of the
intangible cultural heritage, thus helping to
enrich cultural diversity and human
creativity"(UNESCO, 2003, p.1 or also
known as Convention for the Safeguarding
of the Intangible Cultural Heritage).

People should be allowed to participate in all stages of the tourism plan. Meetings should be held publicly to allow local people to speak their minds. When all stakeholders agree, local people should be central actors when the plan is formulated. In addition, local people should be able to obtain equal benefits from tourism activities including, among others, food sellers, local tour guides and boat drivers.

Such direct and indirect actions will increase the pride of being part of the community, maintain a sense of identity, and prevent local people from abandoning their traditions and cultures. 


\section{CONCLUSION}

The concepts of primary and secondary destinations could encourage tourism management companies and tour operators to evaluate the alternatives for tourism activities. It is generally perceived that the value of a primary destination is known and identified while that of a secondary destination is less well known. Therefore, visitors pay much attention to the "icons" of the region or of the country.

By bringing the concept of associated heritage value, the value of the secondary destination can be assessed, which could accentuate the importance of the area. This approach is a possible way for tourism management companies to create new tourist destinations, where associated heritage value is presented as part of experiences gained by tourists in the future. Moreover, it would help decrease a tourism density in a particular destination and promote tourism in a secondary destination by emphasizing the associated heritage value, as suggested for the Baan Lao community in Pakkret, Nonthaburi, a province immediately North of Bangkok, Thailand.

\section{ACKNOWLEDGEMENT}

The authors wish to acknowledge the helpful comments and suggestions of Chi-Lin Chang and Michael McAleer.

\section{REFERENCES}

ASEAN (2000), ASEAN Declaration on Cultural Heritage, http://asccthailand.org/ index.php/ en/mnu-branch-en/mnibranch-amca-en/15-asean-declaration-on-cultural-heritage retrieved on 11 December 2015

Australia ICOMOS (1999), The Burra Charter. The Australian ICOMOS Charter for Places of Cultural Significance, Australia ICOMOS.

Boonpuk, P. (2007), Place Name of Pakkred, Nonthaburi, Sukhothaithammatirat University, Bangkok, Thailand.

Choomgrant, K. (2014), Out of The Closet: An Understanding of 'Queer Heritage' in The Context of Southeast Asia, Unpublished doctoral dissertation, Architectural Heritage Management and Tourism, Faculty of Architecture, Silpakorn University.

Choomgrant, K. (2015a), 'Critical Heritage Usages: A Case of Thailand', Furnace Journal, 1(1), 13-18.
Choomgrant, K. (2015b), 'National Heritage Values in Lao PDR and Singapore: Its Functions and Effects', in Cultural Approach Journal (วารสารกระแสวัฒนธ5รม) July-December 2015 pp. 82-90.

Denes, A. (2012a), 'Mapping Living Heritage at the Phnom Rung Historical Park: Identifying and Safeguarding the Local Meanings of a National Heritage Site', Journal of Siam Society, 100, 183-215.

Denes, A. (2012b), 'The Revitalisation of Khmer Ethnic Identity in Thailand : Empowerment or Confinement?', in P.T. Daly and T. Winter, Tim. Routledge Handbook of Heritage in Asia, London and New York: Routledge, pp. 168-181.

Du Cros, Hilary (2002), 'Conflicting Perspectives on Marketing Hong Kong's Cultural Heritage Tourism Attractions, in Estrategias relativas al patrimonio cultural mundial. La salvaguarda en un mundo globalizado. Principios, practicas y perspectivas. 13th ICOMOS General Assembly and Scientific Symposium. Actas. Comité Nacional Español del, ICOMOS, Madrid, pp. 319-321.

Fine Arts Department (1999), Culture, Historical Development, Identity and Local Wisdom in Nonthaburi (Thai Version), Fine Arts Department: Bangkok

ICOMOS, The Nara Document on Authenticity, http://www.icomos.org/charters/nara-e.pdf retrieved on 15 December 2015

Harrison, R. (2013), Heritage: Critical Approaches, London and New York: Routledge. https://doi.org/10.1093/oxfordhb/9780199602001.013.021

Logan, W.S. (2001), 'Globalizing Heritage: World Heritage as a Manifestation of Modernism and Challenges from the Periphery', in Australia ICOMOS National Conference, 28 November - 1 December 2010 Adelaide, Australia.

Smith, L. (2006), The Uses of Heritage, London and New York: Routledge.

Sullivan, S. (1993), 'The Management of Ancient Chinese Cave Temples, A Site-Management Training Course at the Yungang Grottoes', in Conservation of Ancient Sites on the Silk Road, International Conference on the Conservation of Grotto Sites, October 1993, The J Paul Trust, 1997, pp 2840.

Taylor, K. (2004), 'Cultural Heritage Management: A Possible Role for Charters and Principles in Asia', International journal of Heritage Studies, 10 (5), 417-433. https://doi.org/10.1080/1352725042000299045

Taylor, K. (2010), 'International Practice and Regional Applications in Cultural Heritage Management. Whose Values?', in Cannakale Onsekiz Mart University World Universities Congress Proceeding II, 20-24 October 2010, pp. 13401353.

UNESCO (2003), Convention for the Safeguarding of the Intangible Cultural Heritage. UNESCO Bangkok.

UNESCO Bangkok (2009), Hoi An Protocols for Best Conservation Practice in Asia: Professional Guidelines for Assuring and Preserving the Authenticity of Heritage Sites in the Context of the Cultures of Asia, UNESCO Bangkok.

Yunis, E. (2004), 'Introductory Presentation' in Ministerial Conference on Cultural Tourism and Poverty Alleviation. Hue, Vietnam, 11-12 June 2004

\section{DOI: https://doi.org/10.6000/1929-7092.2017.06.29}

(C) 2017 Choomgrant and Sukharomana; Licensee Lifescience Global.

This is an open access article licensed under the terms of the Creative Commons Attribution Non-Commercial License (http://creativecommons.org/licenses/by-nc/3.0/) which permits unrestricted, non-commercial use, distribution and reproduction in any medium, provided the work is properly cited. 